\title{
Undergraduate osteopathic medical education
}

MARGARET REICH

Senior Staff Editor
The American Osteopathic Association serves as the accrediting body for osteopathic medical education in the United States. All accreditation activities are conducted through the AOA Department of Education by the Bureau of Professional Education and its component groups. (For membership of these committees, see Appendix I, page 1467).

The Bureau is recognized by the US Office of Education as the official accrediting agency for osteopathic medical education. It reports to the AOA Board of Trustees'and to appropriate government and nongovernment agencies.

The Committee on Colleges (COC), a subunit of the Bureau, is responsible for inspecting all colleges of osteopathic medicine. The COC serves as the initial review level in the accreditation process. Based on the results of its reviews and on-site inspections, the COC makes recommendations to the Bureau for approval or disapproval of accreditation status. It also serves as a consulting body should a college request advice on accreditation matters or educational management and policy.

The Bureau, in turn, presents accreditation recommendations to the AOA Board of Trustees, to which it reports. In cases where a college may not agree with a recommendation, the Board serves as a final court of appeal.

The accreditation process involves the examination and evaluation of all aspects of a college of osteopathic medicine (COM), including organization, administration, and finance; faculty and instruction; student admissions, evaluation, and services; curriculum organization; and the nature of the COM's facilities.

Once accredited, a COM must undergo reevaluation approximately every 5 years to maintain its accredited status.

The Basic Standards for Accreditation are published annually in the AOA Yearbook and
Directory of Osteopathic Physicians and are available from the AOA Department of Education.

Currently, 15 fully accredited colleges of osteopathic medicine train future osteopathic physicians (Appendix II, page 1473).

At press time, the statistics discussed in the following sections were the most current as compiled by the American Association of Colleges of Osteopathic Medicine (AACOM).

\section{Faculty}

In 1988-1989, full-time professors, including associate and assistant professors, accounted for $16.8 \%$ of faculty positions, an approximate $2.5 \%$ decline from the previous year. Slightly more than $38 \%$ of the faculty volunteer their services, with the remainder being part-time, paid personnel.

As Table 1 illustrates, general practice/family medicine continues to be the discipline most frequently taught by full-time academicians. Among this group of instructors, $18.3 \%$ are board-certified specialists.

The number of full-time MD faculty members held steady at approximately $14 \%$ during 1988-1989 from the previous year. Likewise, slightly more than $75 \%$ of the faculty have earned at least a DO degree. Meanwhile, the number of $\mathrm{PhD}$ professors dropped from $8.2 \%$ to $7.1 \%$.

\section{Osteopathic medical students Applicants}

In 1988-1989, 3,160 candidates sought an osteopathic medical education, up from 3,030 applicants the year before. Table 2 indicates that increasing numbers of women and minorities compose this population. Hispanic applications have more than quadrupled while more than three times as many blacks applied in 1989 than in 1976. More than one third of all 1989 
Table 1

Full-Time Faculty Assignments, by Discipline*

\begin{tabular}{|lc|}
\hline Discipline & \% of faculty assigned \\
\hline General practice/family medicine & 18.3 \\
Internal medicine & 9.8 \\
Surgery & 2.8 \\
Radiology & 3.0 \\
Pediatrics & 4.5 \\
Psychiatry & 3.1 \\
Obstetrics/gynecology & 3.5 \\
Pathology & 2.8 \\
Physiology & 6.4 \\
Anatomy & 8.0 \\
Biochemistry & 5.5 \\
Microbiology & 4.7 \\
Pharmacology & 4.1 \\
Osteopathic principles & 3.9 \\
Emergency medicine & 2.5 \\
Other & 17.1 \\
& \\
\hline *Source: AACOM 1989 Annual Statistical Report. & \\
\hline
\end{tabular}

applicants were women. In fact, women now make up the largest segment of minority applicants.

As Table 3 shows, the University of Osteopathic Medicine and Health Sciences College of Osteopathic Medicine and Surgery in Des Moines, Ia, received the most applications totaled for 1987-1988, but dropped off to fourth place in 1988-1989, behind Ohio University Col- lege of Osteopathic Medicine, Kirksville College of Osteopathic Medicine, and New York College of Osteopathic Medicine, respectively.

\section{Enrollment}

Freshmen enrollment showed a $5.2 \%$ increase in 1988. Figure 1 illustrates the generally steady climb in the number of freshmen students. This student population peaked at 1,780 in 1988-1989.

Total enrollments for the past 2 years are listed by college in Table 3 . Because a candidate might have applied to more than one college, the numbers may reflect duplicate applicants.

\section{Minorities}

As shown in Figure 2, the ethnic minority population has more than quadrupled since 1976 , and accounts for $17 \%$ of freshmen. The 15 colleges of osteopathic medicine report 813 minority students as members of the total student body. Their distribution is outlined in Table 4 .

\section{Women}

In 1968 , only $2.8 \%$ of all osteopathic medical students were women. Twenty-one years later, that figure has climbed to $30 \%$ (Table 5). The

\begin{tabular}{|c|c|c|c|c|c|c|c|c|c|c|}
\hline \multicolumn{11}{|c|}{$\begin{array}{l}\text { Table } 2 \\
\text { Applicants to AACOMAS Osteopathic Medical Schools-Ethnic } \\
\text { Groups and Women by Entering Year* }\end{array}$} \\
\hline Group & 1976 & 1978 & 1980 & 1982 & $1984^{\dagger}$ & 1985 & 1986 & 1987 & 1988 & 1989 \\
\hline $\begin{array}{l}\text { Black American } \\
\text { American Indian/Alaskan }\end{array}$ & 59 & 116 & 130 & 150 & 136 & 145 & 159 & 170 & 208 & 221 \\
\hline Native & 14 & 18 & 15 & 16 & 27 & 21 & 31 & 19 & 20 & 20 \\
\hline Hispanic & 33 & 38 & 76 & 128 & 140 & 170 & 164 & 165 & 153 & 177 \\
\hline $\begin{array}{l}\text { Total underrepresented } \\
\text { minority } \\
\text { Percent underrepresented }\end{array}$ & 106 & 172 & 221 & 294 & 303 & 336 & 354 & 354 & 381 & 418 \\
\hline minority & 2.9 & 4.9 & 5.8 & 7.5 & 7.3 & 8.7 & 10.1 & 10.6 & 12.6 & 13.2 \\
\hline $\begin{array}{l}\text { White, non-Hispanic } \\
\text { Asian American/Pacific }\end{array}$ & 3,539 & 3,299 & 3,467 & 3,484 & 3,633 & 3,332 & 2,946 & 2,684 & 2,376 & 2,404 \\
\hline Islander & 62 & 59 & 98 & 139 & 190 & 201 & 215 & 288 & 273 & 338 \\
\hline Total all groups & 3,707 & 3,530 & 3,786 & 3,917 & 4,126 & 3,869 & 3,515 & 3,326 & 3,030 & 3,160 \\
\hline $\begin{array}{l}\text { No. of women among } \\
\text { total applicants }\end{array}$ & $\doteqdot$ & 610 & 804 & 965 & 1,168 & 1,102 & 1,010 & 1,002 & 966 & 1,068 \\
\hline Percent Women & $\ddagger$ & 17.3 & 21.2 & 24.6 & 28.3 & 28.5 & 28.7 & 30.2 & 31.9 & 33.8 \\
\hline $\begin{array}{l}\text { *Source: AACOM Annual Statistica } \\
\text { † Starting } 1984 \text {, white non-Hispanic } \\
\text { † Not available. }\end{array}$ & $\begin{array}{l}\text { ort. } \\
\text { inclu }\end{array}$ & 1 & . & & & 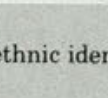 & cation. & & & \\
\hline
\end{tabular}


Table 3

Number of Applications Received, First-Year Enrollment, and Total Enrollment by School*

\begin{tabular}{|c|c|c|c|c|c|c|}
\hline \multirow[b]{2}{*}{ School } & \multicolumn{2}{|c|}{$\begin{array}{c}\text { No. of } \\
\text { applications }\end{array}$} & \multicolumn{2}{|c|}{$\begin{array}{l}\text { First-year } \\
\text { enrollment }\end{array}$} & \multicolumn{2}{|c|}{$\begin{array}{c}\text { Total } \\
\text { enrollment }\end{array}$} \\
\hline & $\begin{array}{l}1987- \\
1988\end{array}$ & $\begin{array}{c}1988- \\
1989\end{array}$ & $\begin{array}{c}1987- \\
1988\end{array}$ & $\begin{array}{c}1988- \\
1989\end{array}$ & $\begin{array}{c}1987- \\
1988\end{array}$ & $\begin{array}{c}1988- \\
1989\end{array}$ \\
\hline CCOM & 722 & 645 & 108 & 126 & 393 & 416 \\
\hline COM-OSU & 764 & 543 & 65 & 73 & 282 & 271 \\
\hline COMP & 947 & 866 & 103 & 111 & 411 & 419 \\
\hline $\mathrm{KCOM}$ & 1,201 & 1,170 & 133 & 138 & 526 & 531 \\
\hline MSU-COM & 823 & 738 & 125 & 123 & 505 & 507 \\
\hline NYCOM & 1,177 & 1,122 & 132 & 154 & 515 & 541 \\
\hline OUCOM & 1,061 & 1,237 & 107 & 100 & 390 & 377 \\
\hline PCOM & 925 & 830 & 204 & 212 & 814 & 808 \\
\hline SUHSCOM & 1,083 & 843 & 103 & 111 & 400 & 402 \\
\hline TCOM & 810 & 739 & 103 & 94 & 385 & 391 \\
\hline UHS-COM & 365 & 285 & 129 & 134 & 532 & 500 \\
\hline UMDNJ-SOM & 772 & 746 & 59 & 63 & 220 & 220 \\
\hline UNECOM & 1,057 & 943 & 80 & 79 & 287 & 300 \\
\hline UOMHS/COM & 1,393 & 1,117 & 178 & 193 & 693 & 703 \\
\hline WVSOM & 926 & 843 & 63 & 64 & 233 & 233 \\
\hline Total & 14,026 & 12,660 & 1,692 & 1,780 & 6,586 & 6,614 \\
\hline
\end{tabular}

*Source: AACOM 1989 Annual Statistical Report.

tThe number of applicants indicated above is not unduplicated, as in Table 2. The same applicant reported here may be listed by several schools.

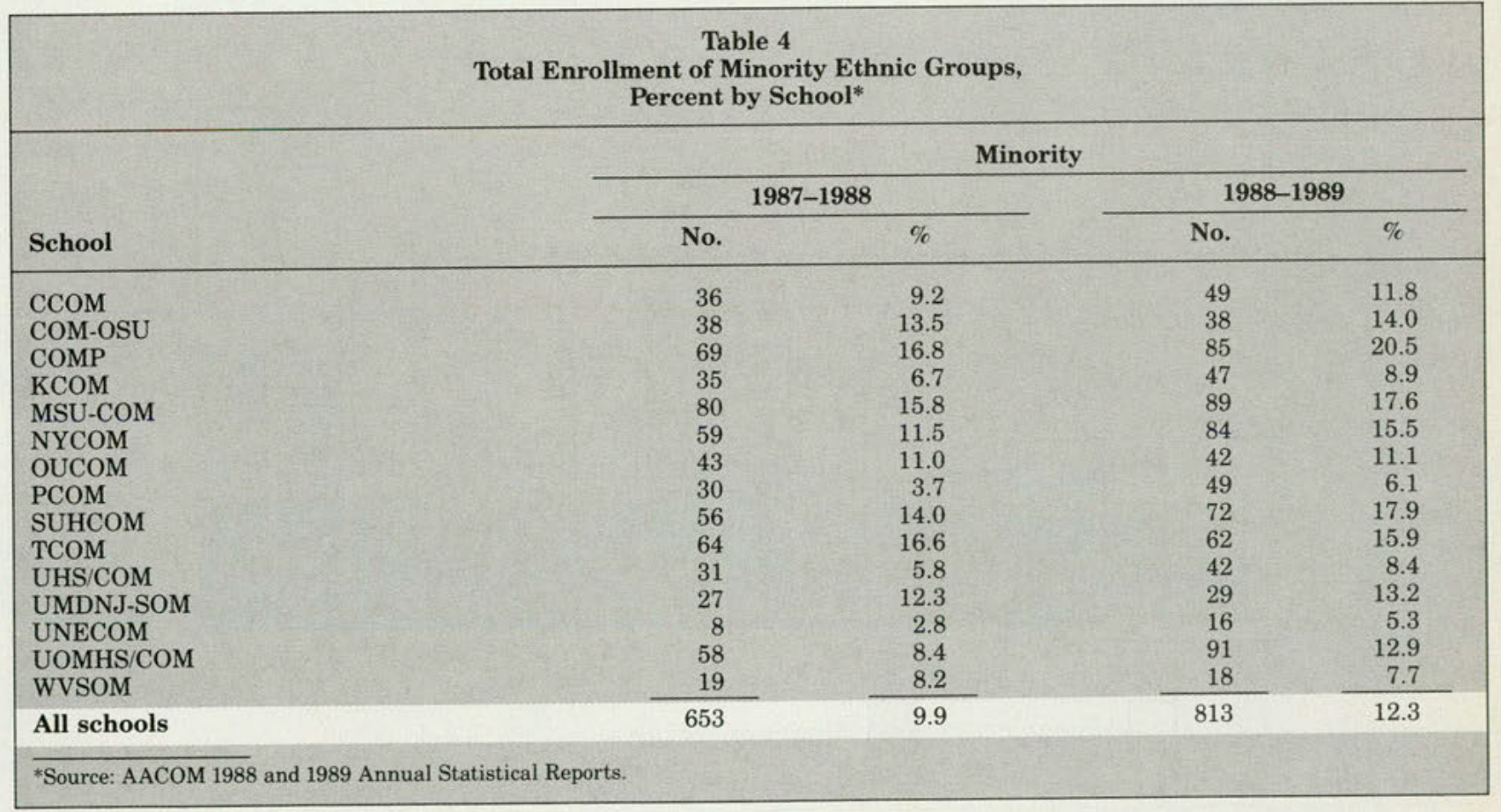




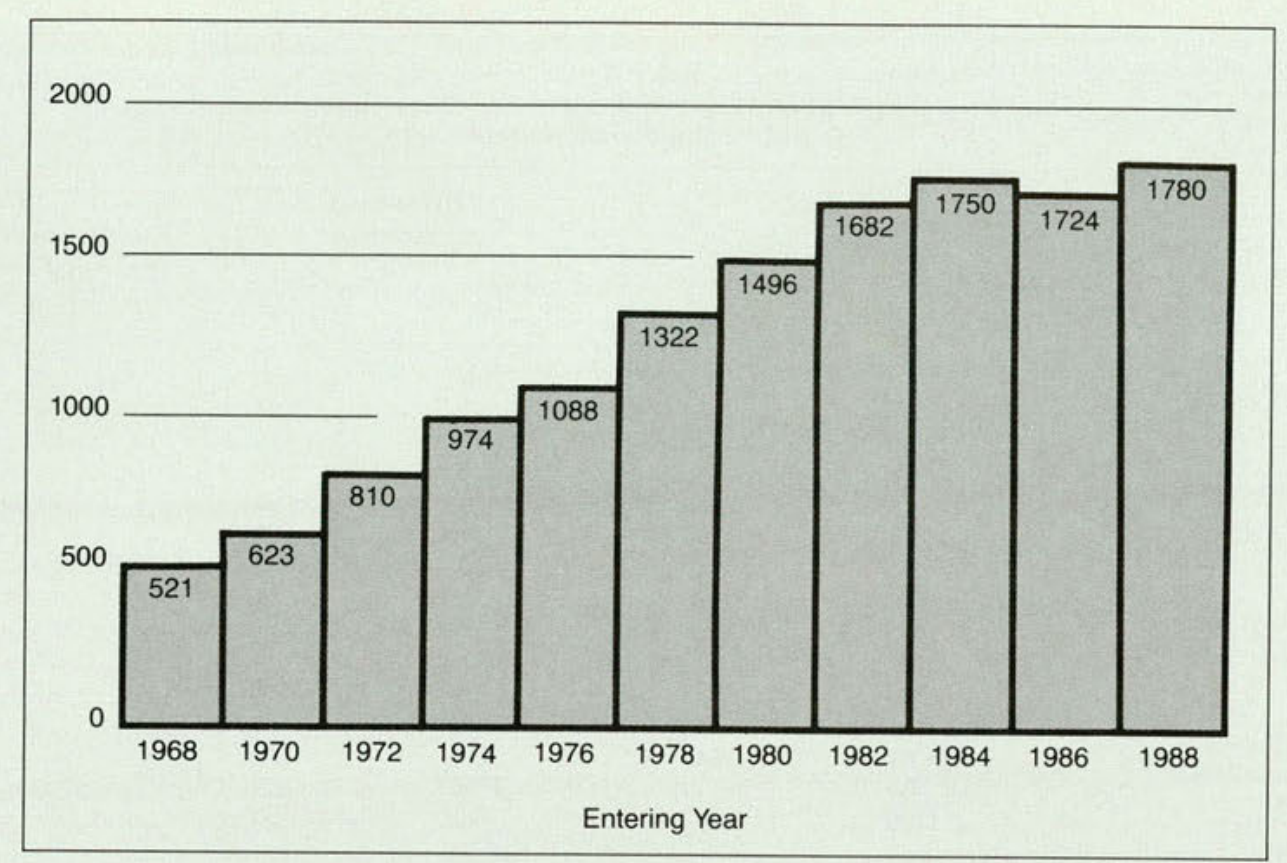

Figure 1. Freshmen enrollment, alternate years, 1968 to 1988. (From AACOM 1989 Statistical Report.)

\section{Percentages}

15

10
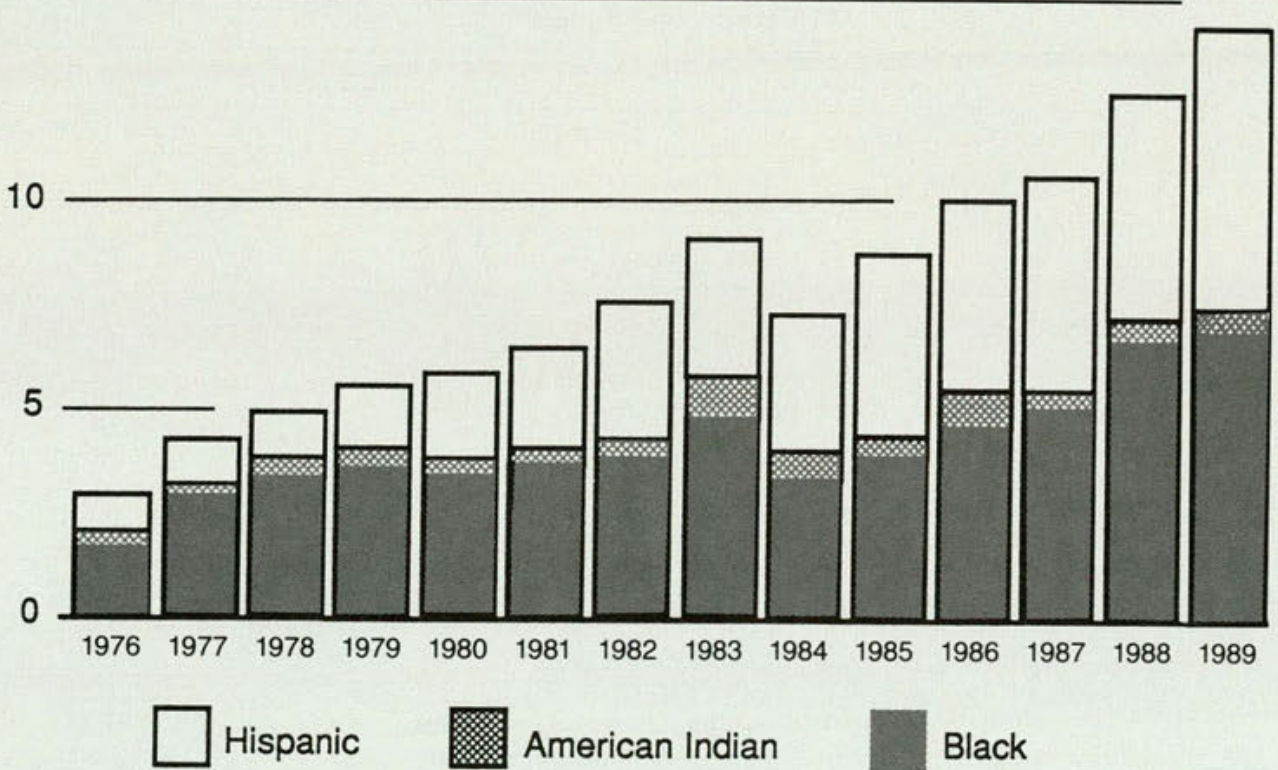

American Indian

Black

Figure 2. Percentages of ethnic enrollment. (From AACOM 1989 Statistical Report.) 


\begin{tabular}{|c|c|c|c|c|c|c|}
\hline \multicolumn{7}{|c|}{$\begin{array}{c}\text { Table } 5 \\
\text { Women Enrollment* }\end{array}$} \\
\hline \multirow[b]{2}{*}{ Entering year } & \multicolumn{3}{|c|}{ Total enrollment } & \multicolumn{3}{|c|}{ Graduates } \\
\hline & Total & No. of women & $\%$ women & Total & No. of women & $\%$ women \\
\hline 1968 & 1,879 & 53 & 2.8 & 427 & 8 & 1.9 \\
\hline 1969 & 1,997 & 59 & 3.0 & 432 & 12 & 2.8 \\
\hline 1970 & 2,151 & 61 & 2.8 & 472 & 11 & 2.3 \\
\hline 1971 & 2,304 & 79 & 3.4 & 485 & 18 & 3.7 \\
\hline 1972 & 2,579 & 116 & 4.5 & 649 & 18 & 2.8 \\
\hline 1973 & 2,780 & 181 & 6.5 & 594 & 17 & 2.9 \\
\hline 1974 & 3,139 & 267 & 8.5 & 702 & 44 & 6.3 \\
\hline 1975 & 3,443 & 362 & 10.5 & 809 & 58 & 7.2 \\
\hline 1976 & 3,671 & 472 & 12.9 & 908 & 84 & 9.3 \\
\hline 1977 & 3,926 & 570 & 14.5 & 971 & 68 & 7.0 \\
\hline 1978 & 4,221 & 688 & 16.3 & 1,004 & 163 & 16.2 \\
\hline 1979 & 4,571 & 789 & 17.3 & 1,059 & 192 & 18.1 \\
\hline 1980 & 4,940 & 971 & 19.7 & 1,151 & 202 & 17.6 \\
\hline 1981 & 5,304 & 1,108 & 20.9 & 1,017 & 186 & 18.3 \\
\hline 1982 & 5,822 & 1,317 & 22.6 & 1,317 & 261 & 19.8 \\
\hline 1983 & 6,212 & 1,526 & 24.6 & 1,287 & 262 & 20.4 \\
\hline 1984 & 6,547 & 1,707 & 26.1 & 1,474 & 344 & 23.3 \\
\hline 1985 & 6,608 & 1,799 & 27.2 & 1,560 & 392 & 25.1 \\
\hline 1986 & 6,640 & 1,853 & 27.9 & 1,587 & 412 & 26.0 \\
\hline 1987 & 6,586 & 1,904 & 28.9 & 1,588 & 395 & 24.9 \\
\hline 1988 & 6,614 & 1,986 & 30.0 & 1,617 & 485 & 30.0 \\
\hline
\end{tabular}

Philadelphia College of Osteopathic Medicine has the largest female student population (274), whereas Michigan State UniversityCollege of Osteopathic Medicine and the University of Medicine and Dentistry of New Jersey-have the highest proportion of women enrolled ( $37.3 \%$ each).

\section{Geographic source of entering students}

Most students $(61.5 \%)$ choose to attend the osteopathic medical school in their home state. Texas College of Osteopathic Medicine has the highest proportion of native students: Only about $5 \%$ are from out of state (Table 6 ).

Financial reasons, family ties, and plans for establishing a practice where continuing education is less costly influenced the students' choice to remain in their home state.

\section{Students admitted with advanced standing}

The baccalaureate degree was the highest degree earned by $85.3 \%$ of the 1988 incoming freshmen, a small dip from 1987 levels in which nearly nine out of ten freshmen held this degree. Those with a master's degree numbered $8 \%$, a slight increase from the previous year. Approximately $1.4 \%$ of students in the 1988 freshmen class had earned the doctorate.

\section{Freshmen college record}

The mean grade point average for first-year students dropped slightly, from 3.19 in 1987 to 3.13 in 1988 . In 1988, MCAT average scores for each of the following disciplines were as follows: biology, 7.6; chemistry, 6.9; physics, 7.0 ; science, 7.0 ; reading, 7.1 ; and quantitative operations, 6.7. Scores for each discipline declined from the previous year.

\section{Student evaluation}

Composite class rank, numerical rank, and letter grade determine student evaluation. AACOM reports nine colleges gauge student progress using results from the National Board Examinations. Three institutions require students pass Part I of the National Board Examinations for advancement or graduation; at 


\begin{tabular}{|c|c|c|c|}
\hline \multicolumn{4}{|c|}{$\begin{array}{c}\text { Table } 6 \\
\text { Number of State Residents and Nonresidents } \\
\text { Enrolled, by School* }\end{array}$} \\
\hline College & Resident & Nonresident & Total \\
\hline CCOM & 249 & 167 & 416 \\
\hline COMOSU & 245 & 26 & 271 \\
\hline COMP & 264 & 150 & 414 \\
\hline KCOM & 89 & 442 & 531 \\
\hline MSU/COM & 430 & 77 & 507 \\
\hline NYCOM & 462 & 79 & 541 \\
\hline OUCOM & 346 & 31 & 377 \\
\hline PCOM & 595 & 213 & 808 \\
\hline SUHSCOM & 294 & 108 & 402 \\
\hline TCOM & 370 & 21 & 391 \\
\hline UHS/COM & 114 & 386 & 500 \\
\hline UMDNJ/SOM & 200 & 20 & 220 \\
\hline UNECOM & 140 & 160 & 300 \\
\hline UOMHS/COMS & 124 & 579 & 703 \\
\hline WVSOM & 147 & 86 & 233 \\
\hline Total & $4,069 \dagger$ & 2,545 & 6,614 \\
\hline
\end{tabular}

least one requires a passing grade in Part II. Feedback from preceptors and hospital personnel provide further information concerning student performance.

Considering these criteria, AACOM reports that only about $2.2 \%$ of students withdrew or were dismissed from osteopathic medical colleges in 1988. Academic difficulty was the most-often cited reason for student attrition.

\section{Osteopathic medical curriculum}

Preparing the physicians of tomorrow for general practice of osteopathic medicine remains the colleges' primary goal. However, training in specialized medicine is not overlooked by any college of osteopathic medicine.

The DO degree is awarded after completion of a 4-year curriculum. During the first 2 years, emphasis is placed on the basic sciences - anatomy, biochemistry, embryology, his- tology, immunology, microbiology, pathology, and physiology. Several colleges also offer introductory courses in clinical studies, such as general practice, neurology, obstetrics and gynecology, osteopathic manipulation, pediatrics, psychiatry, and surgery.

Geriatrics, nutrition, health promotion, drug therapy, bioethics, and biomechanics are now incorporated into the osteopathic medical curriculum, as is computer use in medicine.

Clinical practice, in the form of preceptorships, clerkships, and clinical rotations, occurs in the third and fourth years of the osteopathic medical school curriculum.

Each college has a different policy concerning electives. Most schools permit taking electives during the third year, although a few colleges allow first-year students to do so. Specialized or advanced training courses constitute acceptable electives. 
The \#1 prescribed allergy

\section{prod}

RAPID,

UNSURPASSED RELIEF

Relief starts fast - most hay fever patients experience significant relief within 1 hour $^{1+}$

Relief peaks fast - within 3-4 hours ${ }^{2 * *}$

Relief is unsurpassed - proven in 30 double-blind clinical studies ${ }^{3-7}$

Relief is convenient - for high patient compliance ${ }^{\dagger \dagger}$

(terfenadine) $60 \mathrm{mg}$ table

\section{The ideal profile for fast, on-the-job relief}

- Based upon worldwide prescription and distribution information (1986-1988)-data on file.

t In most hay fever patients $(55 \%)$.

* In studies using the histamine-induced skin wheal test.

tt A summary of 26 studies relating compliance and dosage schedules of various types of medications

showed no significant difference in compliance rates between q.d. and b.i.d. dosing. There was significantly greater compliance with q.d. or b.i.d dosing compared to t.i.d. or q.i.d. dosing $(p<0.05)^{.}$

(c) 1989. Merrell Dow Pharmaceuticals Inc.

Before prescribing Seldane, please see Brief Summary of Prescribing Information, which appears on the reverse side. 

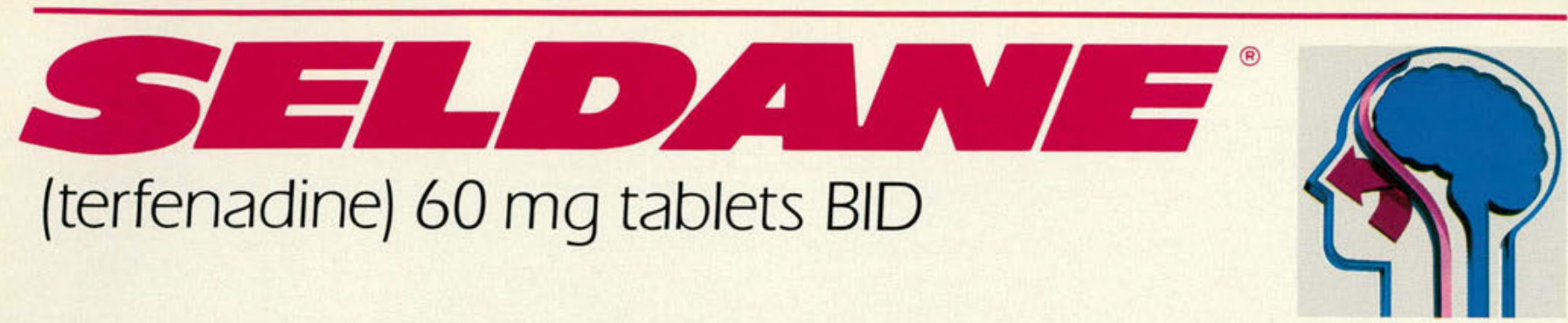

\section{Fast, unsurpassed relief}

- Efficacy maintained in through-the-season use ${ }^{9-11}$ - Lets patients stay alert so they can perform at their best

B.i.d. dosing for high patient compliance

Seldane ${ }^{\circledR}$ (terfenadine) 60 mg Tablets

CAUTION: Federal law prohibits dispensing without prescription.

DESCRIPTION

Seldane (terfenadine) is available as tablets for oral administration. Each tablet contains $60 \mathrm{mg}$ terfenadine. Tablets also contain, as inactive ingredients: corn starch, gelatin, lactose, magnesium stear ate, and sodium bicarbonate.

INDICATIONS AND USAGE

Seldane is indicated for the relief of symptoms associated with seasonal allergic rinitis such as sneezing, rinorrhea, pruritus, and lacrimation.

\section{CONTRAINDICATIONS}

Seldane is contraindicated in patients with a known hypersensitivity to terfenadine or any of its ingre-

dients.

\section{PRECAUTIONS}

Information for patients

Patients taking Seldane should receive the following information and instructions. Antihistamines are prescribed to reduce allergic symptoms. Patients should be questioned about pregnancy or lactation before starting Seldane therapy, since the drug should be used in pregnancy or lactation only it the potential benefit justifies the potential risk to tetus or baby. Patients should be instructed to take Seldane
only as needed and not to exceed the prescribed dose. Patients should also be instructed to store this medication in a tightly closed container in a cool, dry place, away from heat or direct sunlight, and away medication in
from children

Carcinogenesis, mutagenesis, impairment of fertility

Oral doses of terfenadine, corresponding to 63 times the recommended human daily dose, in mice for 18 months or in rats for 24 months, revealed no evidence of tumorigenicity. Microbial and micronucleus test assays with terfenadine have revealed no evidence of mutagenesis.

Reproduction and fertility studies in rats showed no effects on male or female fertility at oral doses of up to 21 times the human daily dose. At 63 times the human daily dose there was a small but significan reduction in implants and at 125 times the human daily dose reduced implants and increased post-implantation losses were observed, which were judged to be secondary to maternal toxicity.

Pregnancy Category $C$

There was no evidence of animal teratogenicity. Reproduction studies have been performed in rats at doses 63 times and 125 times the human daily dose and have revealed decreased pup weight gain an survival when tertenadine was administered throughout pregnancy and lactation. There are no adequate and well-controlled studies in pregnant women. Seldane should be used during pregnancy only if the potential benefit justifies the potential risk to the fetus.

Nonteratogenic effects

Seldane is not recommended for nursing women. The drug has caused decreased pup weight gain and survival in rats given doses 63 times and 125 times the human daily dose throughout preonancy and lactation. Effects on pups exposed to Seldane only during lactation are not known, and there are no adequate and well-controlled studies in women during lactation.

Pediatric use

Safety and effectiveness of Seldane in children below the age of 12 years have not been established.

General

Consideration should be given to potential anticholinergic (drying) effects in patients with lower airway disease, including asthma.

ADVERSE REACTIONS

Experience from clinical studies, including both controlled and uncontrolled studies involving more than 2,400 patients who received Seidane, provides information on adverse experience incidence for periods of a few days up to six months. The usual dose in these studies was $60 \mathrm{mg}$ twice daily, but in a small number of patients, the dose was as low as $20 \mathrm{mg}$ twice a day, or as high as $600 \mathrm{mg}$ daily.

In controlled clinical studies using the recommended dose of $60 \mathrm{mg}$ b.i.d., the incidence of reported adverse effects in patients receiving Seldane was similar to that reported in patients receiving placebo. (See Table below.)

ADVERSE EVENTS REPORTED IN CLINICAL TRIALS

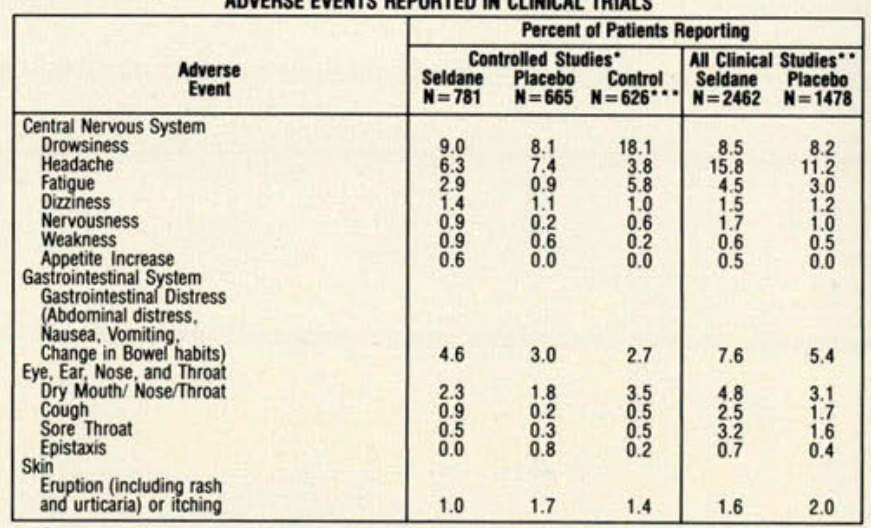

"Duration of treatment in "CONTROLLED STUDIES" was usually 7-14 DAYS

- Duration of treatment in "ALL CLINICAL STUDIES" was up to 6 months. "CONTROL

In addition to the more frequent side effects reported in clinical trials (See Table), adverse effects have been reported at a lower incidence in clinical trials and/or spontaneously during marketing of Seldane that warrant listing as possibly associated with drug administration. These include: alopecia, (hair loss or thinning), anaphylaxis, angioedema, arrhythmia (including ventricular tachyarrhythmia), bronchospasm, confusion, depression, galactorrhea hypotension, insomnia menstrua disorders (including dysmenorrinea), musculoskeletal symptoms, nightmares, paloitation, paresthesia, photosensitivity, prolonged $Q T$ interval, seizures, sweating, syncope, tachycardia, tremor, urinary frequency, and visual disturbances. In clinical trials, several instances of mild or in one case, moderate transaminase elevations were seen in patients receiving Seldane. Mild elevations were also seen in placebo treated patients. Marketing experiences include isolated reports of jaundice, cholestatic hepatitis, and hepatitis; in most cases available information is incomplete. In neither the clinical trials nor marketing experience is a causal relationship of liver abnormalities to Seldane use clear. OVERDOSAGE

Information concerning possible overdosage and its treatment appears in Full Prescribing Information. DOSAGE AND ADMINISTRATION

The usual dosage for adults and children 12 years and older is $60 \mathrm{mg}$ (1 tablet) twice daily. Product Information as of June, 1988

Y352D MERRELL DOW PHARMACEUTICALS INC.

Subsidiary of The Dow Chemical Company

Cincinnati, Ohio 45215, U.S.A.

Merrell Dow

PRINTED IN U.S.A.

References: 1. Murphy-O'Connor JC. Renton RL. Westlake DM: Comparative trial of two dose regimens of terfenadine in patients with hay fever. J Int Med Res 1984:12:333-337. 2. Huther KJ, Renftle G. Barraud N, et al: Inhibitory activity of terfenadine on histamine-induced skin wheals in man. Eur J Clin Pharmacol 1977:12:195-199. 3. Kemp JP. Buckley CE. Gershwin ME, et al: Multicenter, double-blind, placebo-controlled trial of terfenadine in seasonal allergic rhinitis and conjunctivitis. Ann Allergy 1985:54:502-509.4. Backhouse CI. Brewster BS, Lockhart JDF, et al: Terfenadine in allergic rhinitis. A comparative trial of a new

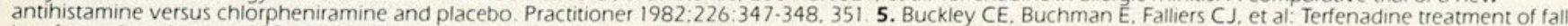

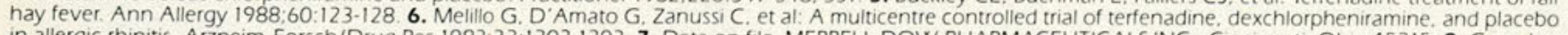

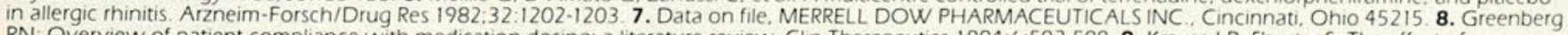
RN: Overview of patient compliance with medication dosing: a literature review. Clin Therapeutics 1984:6:592-599.9. Krause LB. Shuster S: The effect of terfenadine on dermographic wealing. Br J Dermatol 1984:10:73-79. 10. Kemp JP. Falliers CJ. Fox RW, et al: A multicenter, open study of the non-sedating

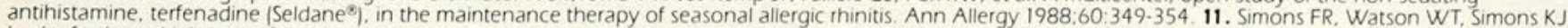
Lack of subsensitivity to terfenadine during long-term treatment. J Allergy Clin Immunol 1988:82:1068-1075 